\title{
Research on Seismic Performance of New Prefabricated Strengthen-weaken Beam-column Connection Joints
}

\author{
LI Xin ${ }^{1}$, ZHANG Xiaojie ${ }^{1, *}$, TAO Xudong ${ }^{2}$ \\ ${ }^{1}$ School of Civil Engineering, Shandong University of Architecture, Jinan, Shandong, 250101, China \\ ${ }^{2}$ School of Civil Engineering, Qingdao University of Technology, Qingdao, Shandong, 266033, China
}

\begin{abstract}
In order to realize the design concept of "strengthened column and weakened beam, strengthened connection joints and weakened components" and ensure the improvement of joints' bearing capacity and the transfer of plastic hinges along beams far away from column ends, this paper proposes a new type of prefabricated beams with strengthen-weaken beam-column connection, and changes multiple parameters. Six connection joint models are designed for finite element analysis. The results show that: JD-1 is located far away from the column end according to the plastic development trend, which is in line with the purpose of transfer of the plastic hinges at the beam end. In addition, the whole column is barely damaged during the whole loading process of this connection joint, and quick recovery after the earthquake could be realized merely by replacing other related components of the joint in the later period. Changes of different parameters also have certain impact on the bearing capacity, seismic resistance and energy dissipation capacity of the joint.
\end{abstract}

\section{Introduction}

There are serious environmental pollution and waste of resources in the development of traditional extensive-style buildings. In order to adhere to the sustainable development of the construction industry, prefabricated buildings have become an inevitable choice to realize the transformation and development. Prefabricated steel construction buildings are prefabricated buildings whose structural system is composed of steel members. Compared with concrete structures, the steel structure has the advantages of light weight, good seismic performance, recyclable resources, reduction of environmental pollution, etc. As its processing plants can realize modular and standardized production of components, the steel structure is the preferred choice for developing industrialized prefabricated buildings ${ }^{[1-3]}$.

This paper presents a new type of prefabricated strengthen-weaken beam-column connection joint. The joint is strengthened by the external diaphragms at the column ends and meanwhile the flange at the beam ends adopts dog-bone weakening. The finite element analysis software is used to change the parameters such as whether the beam with flanges is weakened or not, the weakening length of the beams with dog-bone weakening, the weakening depth of the beam with dog-bone weakening, the thickness of the square steel tube column, and the presence of the diaphragm inside the column. A total of 6 different forms of connection joints between square steel tube columns and $\mathrm{H}$-shaped steel beams are designed for comparative analysis, with emphasis on the impact of these parameter changes on the seismic performance of the new type of joints proposed, including the bearing capacity, stiffness degradation, energy dissipation, etc.

\section{Design of Connection Joints Model}

In this paper, a new type of prefabricated strengthenweaken beam-column connection joint is designed focusing on square steel tube column, external diaphragms and $\mathrm{H}$-shaped steel beam members with dog-bone weakening cross section, as shown in Figure 1. The specimens shown in the figure are all processed in advance in the plants. The fillet radius of the column foot of the square steel tube column is $36 \mathrm{~mm}$, which refers to the national standard of "Cold drawn shaped steel tubes". Parts are spliced on the construction site, of which the external diaphragm is welded with the square steel tube column and the beam with flanges, and the web of the external diaphragm is connected with the web of the beam by bolted joints. The bolted joints adopts the high tensile M20 bolts of the grade 10.9 grade, and the size of bolts and web gasket is in accordance with the literature ${ }^{[4-5]}$.

\footnotetext{
* Corresponding author e-mail: zxj@sdjzu.edu.cn
} 


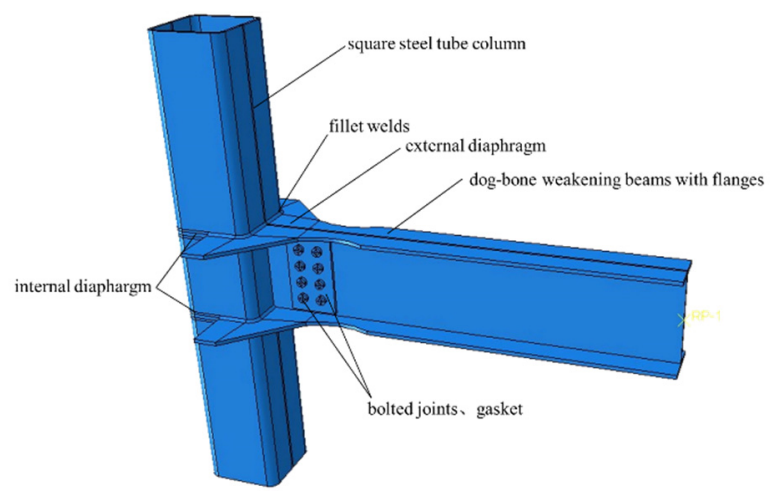

Figure 1. Strengthen-weaken beam-column connection of prefabricated beam ends

This new type of joint strengthens the core area of the joint and weakens the flange's cross section of the beam at the same time. It ensures that the bearing capacity is improved, the weak parts are far away from the column ends, and the plastic hinge is transferred outward from the column end, thus securing the design concept of "strengthening column and joints and weakening beams and components". Meanwhile, it is found that the whole column hardly yields when the beam faces ductile failure, so the column as the main load-bearing member does not need to be replaced, and only other related members of the joint need to be replaced to realize quick recovery of the joint after the earthquake.

\section{An Overview of Connection Designs}

\subsection{Specimen Design}

This paper takes JD-1 as the basic joint, and designs a total of 6 joint models from aspects such as whether the beam

flange has dog-bone weakening, the weakened length changing from the dog-bone beam to cross sectional flanges $b$, and the weakening depth changing from the dog-bone beam to cross sectional flanges $\mathrm{c}$, thickness of square steel tube column, and whether to increase the internal diaphragms inside the column. The impact of the above-mentioned parameter changes on the bearing capacity, stiffness degradation, energy dissipation, recoverable function and other aspects of the joint is investigated. See Table 1 for the joint number and basic dimensions of the joints. Compared with the basic joint JD-1, JD-2 adopts beams that have no dog-bone weakening; JD-3 increases the dog-bone weakening length of beam flanges; JD-4 increases the dog-bone weakening depth of beam flanges; JD-5 increases the thickness of square steel tube column; and JD-6 is equipped with 2 internal diaphragms in the square steel tube column, which are in the same horizontal plane as the flange of the external diaphragms and the flange of the beam.

The total length of square steel tube column is $1800 \mathrm{~mm}$. The external diaphragms are symmetrically assembled at the column ends. The dimension of flanges of the external diaphragm refers to literature ${ }^{[6]}$. The length of the H-shaped steel beam not weakened and that of the weakened H-shaped steel beam members with dog-bone flanges are all $1370 \mathrm{~mm}$, which is assembled flush with the external diaphragm. The distance between the beam end and the central axis of the square steel tube column is $330 \mathrm{~mm}$. The external diaphragm is welded with the square steel tube column by fillet weld whose cross section is an isosceles right triangle with the catheti of $10 \mathrm{~mm}$. The dogbone weakening length $b$ of beam flanges and the dogbone weakening depth $\mathrm{c}$ of beam flanges of JD-1 are $250 \mathrm{~mm}$ and $30 \mathrm{~mm}$ respectively, which refers to literature ${ }^{[7]}$. See Figure 2-Figure 6 for details of component dimensions.

Table 1. Basic Information of Specimens

\begin{tabular}{ccccccc}
\hline $\begin{array}{c}\text { Speci- } \\
\text { men }\end{array}$ & $\begin{array}{c}\text { Column } \\
\text { cross-section }\end{array}$ & Beam section & $\begin{array}{c}\text { Weakening } \\
\text { length of flange } \\
\text { b }\end{array}$ & $\begin{array}{c}\text { Weakening } \\
\text { depth of flange } \\
c\end{array}$ & $\begin{array}{c}\text { Thickness of flange } \\
\text { with external } \\
\text { diaphragms }\end{array}$ & $\begin{array}{c}\text { Diaphragm } \\
\text { section inside } \\
\text { the column }\end{array}$ \\
\hline JD-1 & $300 \times 300 \times 12$ & $350 \times 180 \times 9 \times 14$ & 250 & 30 & 12 & $/$ \\
JD-2 & $300 \times 300 \times 12$ & $350 \times 180 \times 9 \times 14$ & 0 & 0 & 12 & $/$ \\
JD-3 & $300 \times 300 \times 12$ & $350 \times 180 \times 9 \times 14$ & 275 & 30 & 12 & $/$ \\
JD-4 & $300 \times 300 \times 12$ & $350 \times 180 \times 9 \times 14$ & 250 & 45 & 12 & $/$ \\
JD-5 & $300 \times 300 \times 14$ & $350 \times 180 \times 9 \times 14$ & 250 & 30 & 12 & $276 \times 276 \times 12$ \\
JD-6 & $300 \times 300 \times 12$ & $350 \times 180 \times 9 \times 14$ & 250 & 30 & & 12 \\
\hline
\end{tabular}

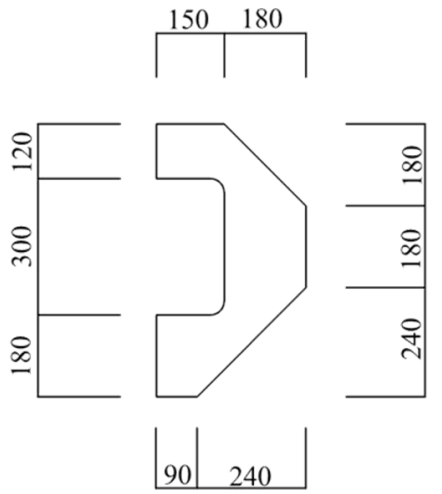

Figure 2. Cross-sectional dimensions of external diaphragms
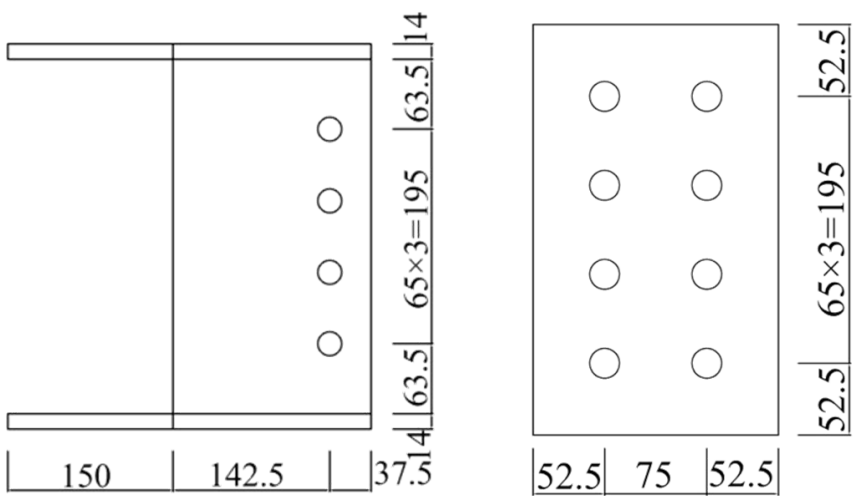

Figure 3. Cross-sectional dimensions of web gasket 


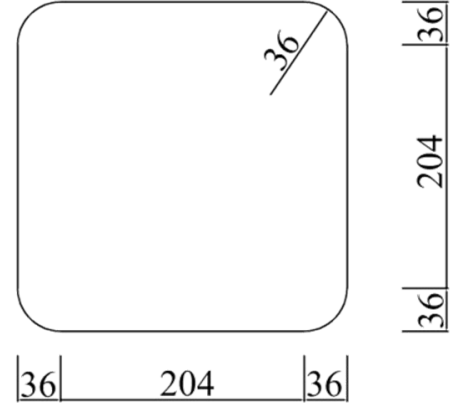

Figure 4. Cross-sectional dimensions of internal diaphragms

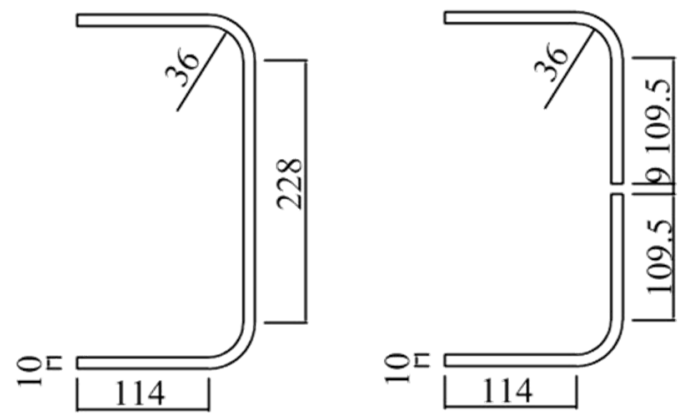

Figure 5. Cross-sectional dimensions of fillet welds

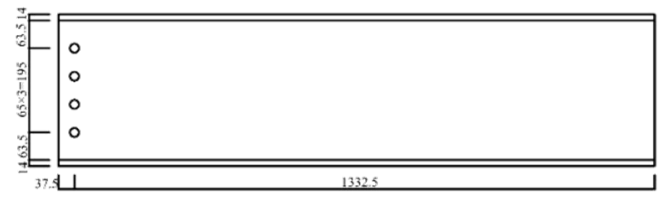

(a) Front elevation view

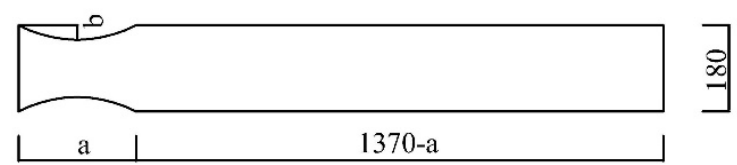

(b) Top view

Figure 6. Cross-sectional dimensions of dog-bone weakening beam with flanges

\subsection{Material Properties}

In this paper, the steel is simulated by isotropic elastoplastic materials, and Mises yield criterion is selected as the initial yield condition. The elastic modulus of materials of different components is 206Gpa and Poisson's ratio is 0.3 . Table 2 shows the plastic parameters of materials of different components. Plastic parameter of internal diaphragms is the same as that of square steel tube column.

Table 2. Plastic Parameters of Materials of Different Parts

\begin{tabular}{llllllllllll}
\hline \multicolumn{2}{c}{$\begin{array}{c}\text { Square steel tube } \\
\text { column }\end{array}$} & \multicolumn{2}{c}{ Welding seam } & \multicolumn{2}{c}{ Flange } & \multicolumn{2}{c}{ Web } & & Gasket & Bolted joint \\
\hline Stress & Strain & Stress & Strain & Stress & Strain & Stress & Strain & Stress & Strain & Stress & Strain \\
412 & 0 & 532.8 & 0 & 296 & 0 & 395 & 0 & 235 & 0 & 945 & 0 \\
435.2 & 0.011 & 541.6 & 0.020 & 300.9 & 0.020 & 400.1 & 0.053 & 281 & 0.024 & 1254 & 0.09 \\
455 & 0.020 & 631.5 & 0.033 & 350.8 & 0.033 & 425.3 & 0.070 & 329 & 0.047 & \\
475.9 & 0.032 & 729.8 & 0.057 & 405.4 & 0.057 & 470.2 & 0.111 & 409 & 0.094 & \\
490 & 0.048 & 810.4 & 0.086 & 450.2 & 0.086 & 521.9 & 0.187 & 472 & 0.138 & \\
510.7 & 0.087 & 900.4 & 0.141 & 500.2 & 0.141 & & & 515 & 0.18 & \\
530 & 0.126 & 1042.5 & 0.274 & 579.2 & 0.274 & & & & & & \\
556.2 & 0.187 & & & & & & & & & &
\end{tabular}

Note: stress and strain in the figure respectively refer to post-yield stress and plastic development strain. The flange includes the external diaphragms and the beams with flanges, and the web includes the external diaphragms and the beam webs.

\subsection{Interaction and Grid Settings}

In this paper, Tie command and surface-to-surface contact are mainly used to simulate the interaction between components. Fillet weld is welded with square steel tube column and external diaphragm respectively by two welds feet, and is simulated by Tie command. Butt welds are arranged between the flange of the external diaphragm and the beam flange, and between the built-in diaphragm and the inner wall of the column, which are simulated by Tie command. The web of the external diaphragm and the beam web are connected by bolted joints. There are contact relations between square steel tube columns and the external diaphragm, and between web of the external diaphragm and beam webs. Tangential behavior and normal behavior are considered in the model. Tangential behavior is defined as "penalty" and being isotropic, with the friction coefficient set to 0.3 , and normal behavior is defined as "hard contact", which allows separation after contact. There is also contact relation between the bolt hole and the bolt bar, but the friction coefficient is no longer considered. The friction coefficient is set to 0 , and the rest of the contact relations is set as above. When the interaction is established, the surface with high stiffness and coarse grid is the master surface.

Different components of the joints adopt solid elements, and the element types are all eight-node brick element with reduced integration (C3D8R). Structured grid is mostly used, some parts adopt sweep, and mapping grid is used in appropriate places. Square steel tube columns, external diaphragms, H-shaped steel beams, gaskets, internal diaphragms, welding seams and bolted 
joints adopt different sizes of global grid which are $30 \mathrm{~mm}$, $20 \mathrm{~mm}, 20 \mathrm{~mm}, 15 \mathrm{~mm}, 10 \mathrm{~mm}, 10 \mathrm{~mm}$ and $2.5 \mathrm{~mm}$ respectively. In addition, local refinement is carried out in the direction of beam flange thickness, direction of beam web thickness, square steel tube column feet and other positions. Different grid densities can ensure the rationality of master-slave surface selection and the calculation speed and accuracy of the model during the interaction.

\subsection{Analysis Steps and Loading Process}

The loading steps of the connections model are as follows: the first step is to apply $155 \mathrm{KN}^{[4]}$ of bolt pretension; the second step is to fix that bolt pretension at the current length; the third step is to apply an axial compression with an axial compression ratio of 0.15 at that top of the column; the fourth step is to apply displacement load at the beam ends, and the distance between the loading point and the center of the column is $1700 \mathrm{~mm}$. Displacement loading adopts the method of setting a reference point at the loading point. The specific operation is to define the reference point at the loading point and establish the kinematic coupling relationship between the reference point and the $\mathrm{H}$-shaped beam end section. At this time, the coupling point is rigidly connected with the beam end section, and application of load on the loading point means applying load to the beam end section.

In order to simulate the hinged column ends, linear displacement is applied to the top and bottom of the square steel tube column. In the third step of analysis step, the vertical deformation of the column is considered under axial compression to constrain the degrees of freedom in $\mathrm{U} 1$ and $\mathrm{U} 2$ directions, while in other cases, the degrees of freedom in three directions are constrained.

Displacement loading control is adopted in the whole loading process. ${ }^{[8]}$ The load is applied based on the interstory drifts of $0.005,0.01,0.02,0.03,0.04,0.05 \mathrm{rad}$, with each level cycling twice. When it exceeds $0.05 \mathrm{rad}$, each level is still loaded in an increment of $0.01 \mathrm{rad}$, and cycles twice. If the specimen reaches the ultimate bearing capacity and has large deformation, the finite element calculation should be stopped. The displacement amplitude and number of cycles of loading at all levels are shown in Table 3.

Table 3. Table of Loading Process

\begin{tabular}{cccc}
\hline $\begin{array}{c}\text { Loading } \\
\text { level }\end{array}$ & $\begin{array}{c}\text { Interstory } \\
\text { drift } \theta / \text { rad }\end{array}$ & $\begin{array}{c}\text { Displacement } \\
\text { amplitude } / \mathrm{mm}\end{array}$ & $\begin{array}{c}\text { Number of } \\
\text { cycles }\end{array}$ \\
\hline 1 & 0.005 & 8.5 & 2 \\
2 & 0.01 & 17 & 2 \\
3 & 0.02 & 34 & 2 \\
4 & 0.03 & 51 & 2 \\
5 & 0.04 & 68 & 2 \\
6 & 0.05 & 85 & 2 \\
$\ldots$ & $\ldots$ & $\ldots$ & 2 \\
\hline
\end{tabular}

\section{Finite Element Analysis}

\subsection{Tendency of Stress and Strain Development of Connections}

Under low cyclic reversed loading, the mechanical performance of joints from JD-1 to JD-6 presents similar characteristics. They all go through the elastic stage, the stage when the plastic hinge appears in the weakened area of the beam flange and develops, the stage of reaching ultimate load and the stage of large deformation and destruction of the specimens. Next it will only describe the stress and strain nephograms of JD-1 in different stages, and analyzes the change of bearing capacity, as well as the formation and development process of plastic hinges.

JD-1: At the initial stage of loading, the dog-bone weakened beam is in the elastic stage, and the beam end load and displacement increase in direct proportion. When the interstory drift is $0.01 \mathrm{rad}$, and the load reaches 138.374 KN, the junction of the column and fillet weld, the corner of the external diaphragm and the outer edge of the weakened area of the beam flange almost yield simultaneously. With the increase of load, the yield range at the corner of the external diaphragm and the deepest part of the beam flange weakening area spreads to the center and the yield areas of the two gradually link up. Then the yield range extends to the junction of the beam web and the beam flange and gradually extends to the center of the beam web. At the first turn of positive loading at the interstory drift of $0.07 \mathrm{rad}$, the joint reaches the ultimate bearing capacity with a load value of $231.11 \mathrm{KN}$. As the load falls back and is loaded inversely, at the first turn of negative loading at the interstory drift of $0.07 \mathrm{rad}$, there is the excessive deformation of flanges near the junction of the external diaphragm flange and the beam flange, near the deepest position of the beam flange weakening area, thus stopping the finite element calculation. At this time, the joint strain nephogram is shown in Figure 7. During the loading process of JD-1, within the range from the corner around the external diaphragm to the end of the extended beam, the two sides of the external diaphragm deflect inward, and the position near the flange of the beam weakened area deflects outward. As the load falls back, such phenomena disappear, and with inverse loading and continuous superposition, finally obvious plastic hinges are formed at the above-mentioned positions. During the whole process of loading of the joints, only the welding seams, external diaphragm and the square steel tube column contact the surrounding positions, the square steel tube column yields locally, and most of the remaining column areas have not reached the yield stress, which indicates that the square steel tube column is barely damaged after the earthquake, thus ensuring the integrity of the bearing members of the steel frame column. In the later period, quick recovery after the earthquake could be realized only by replacing the remaining members of the joint. 


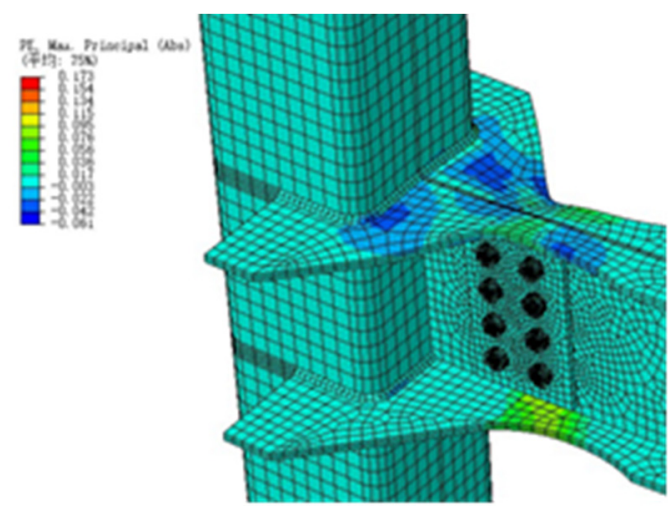

Figure 7. Strain Nephogram of JD-1

\subsection{Hysteretic curves}

The hysteretic curves of all joints are selected from the beginning of loading to the period when the joints have visible large deformation after reaching the ultimate bearing capacity. When observing the curves of independent joints only, we can see that the envelope area of hysteretic curves of each joint is small at the initial loading stage, the joints are in the elastic state, and the seismic performance is not obvious. With the continuous increase of load, the joint members gradually yield, the envelope area of hysteretic curve continuously expands, and its energy dissipation capacity continuously improves. The final hysteretic curves of all joints deflect outward, are full in shape showing no pinch phenomenon, and have large hysteretic area, which presents good energy dissipation capacity.

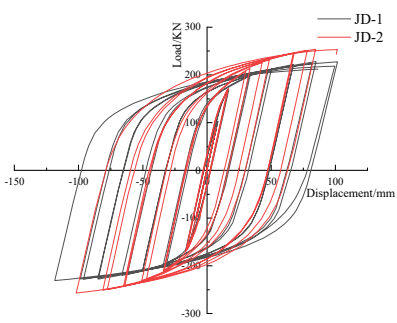

(a) JD-1 and JD-2

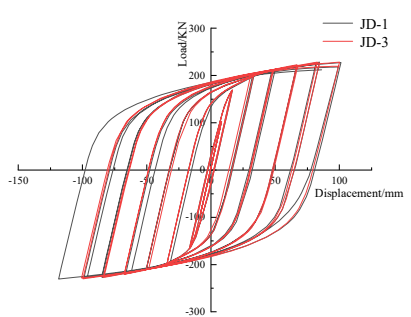

(b) JD-1 and JD-3

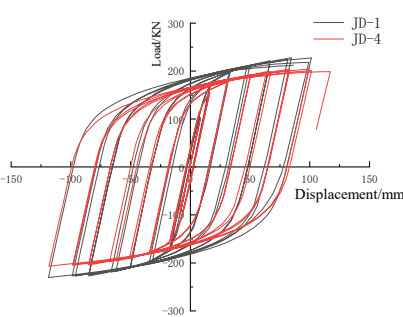

(c) JD-1 and JD-4

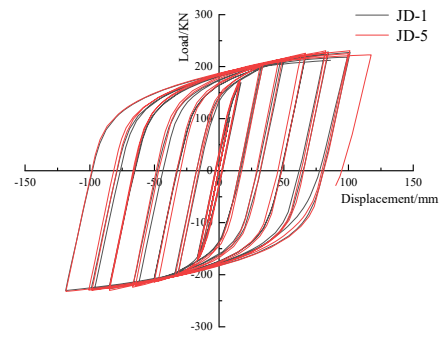

(d) JD-1 and JD-5

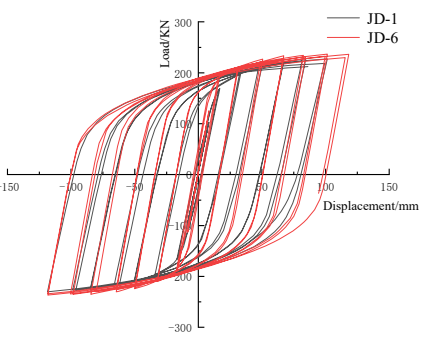

(e) JD-1 and JD-6

Figure 8. Comparison of Hysteretic Curves of Different Connection Joints

Through comparative analysis of the hysteretic curves of other joints and that of JD-1, it can be seen that compared with dog-bone weakened beams in figure 3 (a), the peak bearing capacity of beams not weakened is obviously increased by about $11.2 \%$, while the area of hysteresis loops is relatively smaller, indicating that the seismic resistance and energy dissipation capacity is weakened to some extent. In figure 3(b) and 3(d), the peak bearing capacity of the joint has not changed significantly by increasing the dog-bone weakening length of beams and the column wall thickness. In figure 3(c), the peak bearing capacity is greatly reduced by about $10.2 \%$ by increasing the dog-bone weakening depth of beams.

\subsection{Skeleton Curves}

Skeleton curve is an envelope curve obtained by connecting the load extreme points of each loading (distinguishing positive loading from negative loading) of hysteretic curves in turn. Compared with hysteretic curve, it can more directly reflect the changes of bearing capacity and stiffness of the structure. See figure 9 for comparison of skeleton curves of different joints.

From figure 9, it can be seen that at the initial stage of loading, the joints are all in the elastic state, and the joint load is positively correlated to joint displacement. As the loading continues, the skeleton curve of different joints gradually bifurcates. JD-2 has ultimate bearing capacity of $257.019 \mathrm{KN}$, which is significantly higher than that of other joints, and also has the highest stiffness, belonging to typical reinforced joints. JD-4 has obviously lower ultimate bearing capacity than that of other joints, with the load value of $207.58 \mathrm{KN}$, and the bearing capacity decreases at later period, showing good ductility. It shows that increasing the dog-bone weakening depth of beam flange section can significantly reduce the bearing capacity of the joint, which has certain impact on the transfer of plastic hinges at the beam ends. From the comparison of skeleton curves, the bearing capacity and stiffness of the other four joints have little changes. JD-6 
has a larger stiffness at the initial stage of plastic development, and has a slightly higher bearing capacity than that of the other three joints, which shows that adding internal diaphragms is helpful to increase the initial stiffness and bearing capacity of the joints.

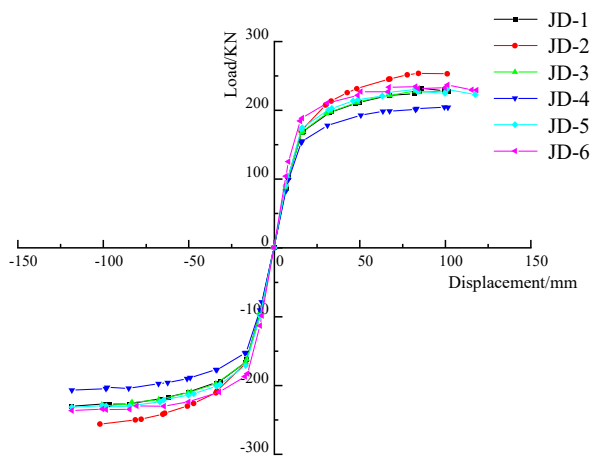

Figure 9. Comparison of Skeleton Curves of Different Joints

\subsection{Stiffness Degradation Curves}

Under the low cycle reversed load, with the increase of joint displacement, the ratio of the sum of absolute values of positive and negative peak loads and the sum of absolute values of displacement in each cycle gradually decreases. This phenomenon is called stiffness degradation of joints. Stiffness degradation is the full manifestation of the specimen entering yield and the material experiencing plastic deformation development. The stiffness degradation curve can reflect the deformation degree and stiffness reduction amplitude of the joint during loading. The stiffness of the specimen is calculated according to secant stiffness. The calculation formula is shown in the following formula (1). See figure 10 for the comparison of stiffness degradation curves of different joints.

$$
K_{\mathrm{i}}=\frac{\left|+F_{i}\right|+\left|-F_{i}\right|}{\left|+X_{i}\right|+\left|-X_{i}\right|}
$$

The formula: $+F_{i}$ and $-F_{i}$ are the load value of the peak forward and reverse points of the $i$ cycle;

$+X_{i}$ and $-X_{i}$ are the displacement value of the peak forward and reverse points of the $i$ cycle.

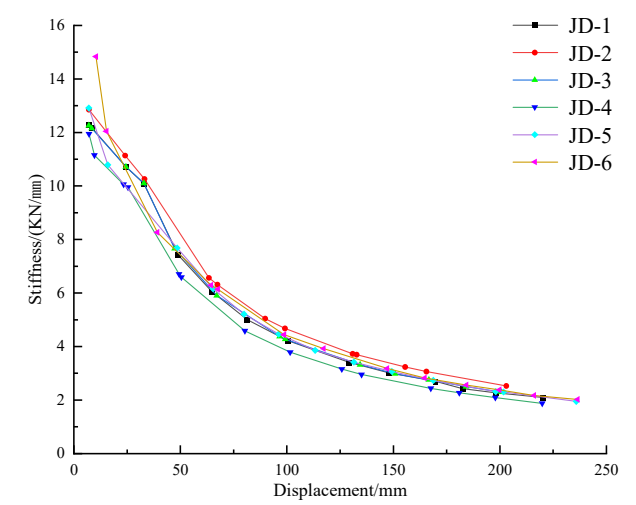

Figure10. Comparison of Stiffness Degradation Curves of Different Joints

From figure 10, it can be seen that JD-6 has the largest initial stiffness and the largest stiffness degradation, indicating that adding the internal diaphragm has a significant effect on improving the initial stiffness and stiffness degradation of the joints and fully enhances the energy dissipation under earthquake. Compared with JD1 and JD-2, JD-5 has slightly higher initial stiffness, which indicates that the initial stiffness can be increased to a certain extent by increased thickness of the square steel tube column and the beams not weakened. JD-4 has the lowest initial stiffness and the lowest final stiffness, which indicates that increasing the dog-bone weakening depth of beam flange has certain impact on reducing the initial stiffness of the joints.

\subsection{Energy Dissipation Analysis of Connection Joints}

Under the low cyclic reversed load, the loading process absorbs energy and the unloading process releases energy. The difference between the two is the energy dissipation of joints in one cycle, and the value is equal to the area surrounded by a hysteresis loop. The energy dissipation capacity of the joint is usually evaluated by the energy dissipation coefficient $\mathrm{E}$ or the equivalent viscous damping coefficient, and the formulas are shown in the following formulas (2) and (3). For different stages of the same joint, the values of energy dissipation capacity are different. In this paper, the hysteresis loop corresponding to the ultimate bearing capacity of the joint is selected to compare the energy dissipation capacity of different joints at this stage. The energy dissipation coefficient $E$ and the equivalent viscous damping coefficient of each joint is calculated, as shown in Table 4.

$$
\begin{gathered}
E=\frac{S_{(A B C+C D A)}}{S_{(O B E+O D F)}} \\
\xi_{e q}=\frac{1}{2 \pi} \cdot \frac{S_{(A B C+C D A)}}{S_{(O B E+O D F)}}
\end{gathered}
$$




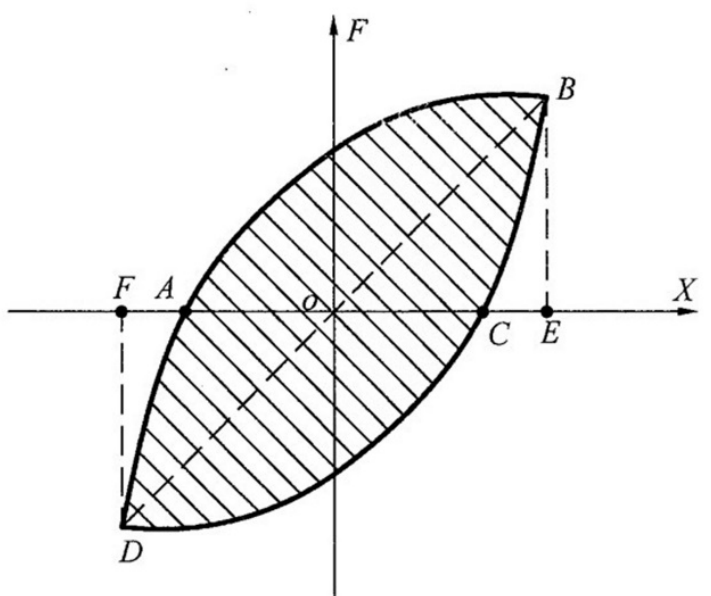

Figure 11. Calculation of Energy Dissipation Coefficient E and Equivalent Viscous Damping Coefficient $\xi_{e q}$

Table 4. Comparison of Energy Dissipation Capacity of Connection Joints

\begin{tabular}{ccc}
\hline $\begin{array}{c}\text { Connection } \\
\text { joints }\end{array}$ & $\begin{array}{c}\text { Energy dissipation } \\
\text { coefficient }\end{array}$ & $\begin{array}{c}\text { Equivalent viscous } \\
\text { damping coefficient }\end{array}$ \\
\hline JD-1 & 2.587 & 0.412 \\
JD-2 & 2.400 & 0.382 \\
JD-3 & 2.537 & 0.404 \\
JD-4 & 2.622 & 0.417 \\
JD-5 & 2.608 & 0.415 \\
JD-6 & 2.644 & 0.421 \\
\hline
\end{tabular}

By comparing the values of energy dissipation coefficient and equivalent viscous damping coefficient in Table 4, it can be seen that compared with JD-1, JD-6 value has the maximum increase, which means that adding the diaphragm inside the column has obviously improved the seismic resistance and energy dissipation capacity. JD4 and JD-5 also increase to a certain extent, which shows that increasing the dog-bone weakening depth of beam flange and the thickness of square steel tube column can improve the seismic resistance and energy dissipation capacity of the joint to a certain extent. The JD-3 value is greatly reduced, which indicates that increasing the dogbone weakening length of the beam flange can weaken the seismic resistance and energy dissipation capacity to some extent. JD-2 has the minimum value, which means that the energy dissipation capacity of its joints is the weakest. According to the comparison of the ultimate bearing capacity of all joints, JD-2 improves the ultimate bearing capacity of the joint to a greater extent at the cost of greatly losing the energy dissipation capacity of the joint.

\section{Conclusions}

This paper, using the finite element method, through the simulated static analysis of reversed cyclic loading applied on the new prefabricated strengthen-weaken columnbeam connection joints, has determined the transfer of plastic hinges as the new joints are under load, and also designed six joints by changing the parameters such as whether the beam has dog-bone weakening, the dog-bone weakening length of the beam flange, the dog-bone weakening depth of the beam flange, the thickness of the square steel tube column, and whether to add the diaphragm inside the column. The changes of the bearing capacity, stiffness degradation capacity and seismic resistance and energy dissipation capacity of the joints under the above-mentioned different parameters are analyzed.

(1) The designed JD-1 is finally destroyed on the flange of external diaphragm or the flange section of the beam weakening area far away from the column end according to the plastic development trend, which is in line with the purpose of transfer of the plastic hinges at the beam end. In addition, the whole column is barely damaged during the whole loading process of this connection joint, and quick recovery after the earthquake could be realized merely by replacing other related components of the joint in the later period.

(2) Comparing the other 5 joints with JD-1 in turn, it can be seen that the peak bearing capacity of the joints can be better improved by around $11.2 \%$ at the cost of great loss of energy dissipation capacity by using beams not weakened. The peak bearing capacity can be greatly reduced by about $10.2 \%$ by increasing the weakening depth of the dog-bone beam flange, which, however, has obvious effect on the further transfer of plastic hinges. Adding the internal diaphragm can effectively improve the stiffness degradation amplitude, energy dissipation coefficient and equivalent viscous damping coefficient of the joint, and obviously enhance the seismic resistance and energy dissipation capacity of the joint. Increasing the dog-bone weakening length of the beam flange has little effect on the peak bearing capacity, but it will advance the occurrence time of the ultimate bearing capacity, which is helpful to improve the ductility of the joint. Increasing the thickness of steel tube columns has certain impact on improving the peak bearing capacity and seismic resistance and energy dissipation capacity of joints.

\section{References}

1. Lin Ying, Wang Yuanqing, Ding Dayi, Shu Chang, Zhang Feng, Liu Wei, Wang Jianhe. Engineering application and research progress of prefabricated steel construction buildings. Institute of Structural Stability and Fatigue, China Steel Construction Society. Proceedings of Academic Exchange and Teaching Seminar of the 17th Session (ISSF-2021). Institute of Structural Stability and Fatigue, China Steel Construction Society. Industrial Construction Magazine Agency, 2021: 5.

2. Su Yikun, Cao Lifei, Zhang Zhibo, Wu Ailin. Research Review and Research Tendency Analysis of Prefabricated Construction Buildings in China. Architecture Technology. 2018, 49(12): 1248-1256.

3. Qin Di, Chen Jinbao. Research on the development and current status of prefabricated steel construction buildings in China. Intelligent City. 2017, 3(11): 1921.

4. GB 50017 - 2017. Standard for Design of Steel Structures. 
5. GBT5782-2016. Hexagon Head Bolts.

6. Mou Ben, Wu Menglong, Mu Zaigen, Wang Junchang. Seismic performance of $\mathrm{H}$-shaped steel beam-tosquare steel corner column connection with external strengthened ring. Chinese Journal of Engineering. 2018, 40(08): 1005-1016.

7. FEMA-350. Recommended seismic design criteria for new steel moment-frame buildings. Washington D C, 2000.

8. AISC, Seismic Provisions for Structural Steel Buildings. American Institute of Steel Construction. INC. July 12, 2016 